\title{
A Study on Prevalence of Domestic Violence among Women in Servant's Quarters of a Tertiary Care Hospital in North India
}

\author{
${ }^{1}$ Arushee Bhatnagar, ${ }^{2}$ Shakti K Gupta, ${ }^{3}$ Gagan Hans, ${ }^{4}$ Vikas H, ${ }^{5}$ Nitin Garg, ${ }^{6}$ Veena Pandey
}

\section{ABSTRACT}

Introduction: Domestic violence (DV) is a major human right and public health problem which can have physical as well as mental health-related adverse effects.

Aim: To study the magnitude, type, and causes of domestic violence against women in the servant's quarters of a tertiary care hospital in North India.

Materials and methods: A questionnaire-based study was conducted in servant's quarters of AlIMS, New Delhi from March 2018 to September 2018 among women of 18 to 65 years. A questionnaire was specifically designed, validated and subsequently used for collecting data on domestic violence. It covered all the information regarding socio-demographic details of the participants as well as their experience with domestic violence. The data collected was then analyzed using the Statistical Package for Social Sciences (SPSS).

Results and discussion: In the study population it was found that $36.4 \%$ (75) women suffered from domestic violence, out of which $35.5 \%$ (71) were married, $4 \%$ (3) unmarried and $1.33 \%$ (1) widow with a mean age of 34 years. It was seen more among young age group, less educated females, early years of marriage, more number of family members living as a joint family and among females having spouses with alcohol addiction. The most common type of abuse was emotional (psychological) followed by physical and economical. Majority of them responded that alcohol addiction and financial difficulties were primary reasons for violence happening more than once in a month in (57.3\%). The most common consequence suffered by females was psychological followed by $17.3 \%$ complaining of severe health effect. $33.4 \%$ of respondents took a corrective step of which only $4 \%$ showed improvement.

\footnotetext{
${ }^{1}$ Intern, ${ }^{2}$ Medical Superintendent, ${ }^{3}$ Assistant Professor, ${ }^{4}$ Senior Resident, ${ }^{5}$ Junior resident, ${ }^{6}$ Statistician

${ }^{1}$ Bharati Vidyapeeth Medical College, Pune, Maharashtra, India

${ }^{2} \mathrm{Dr}$ RP Centre, All India Institute of Medical Sciences, New Delhi, India

${ }^{3}$ Department of Psychiatry, All India Institute of Medical Sciences, New Delhi, India

${ }^{4-5}$ Department of Hospital Administration, All India Institute of Medical Sciences, New Delhi, India

${ }^{6}$ All India Institute of Medical Sciences, New Delhi, India
}

Corresponding Author: Arushee Bhatnagar, Intern, Bharati Vidyapeeth Medical College, Pune, Maharashtra, India, e-mail: arusheemedico999@gmail.com
Conclusion: Domestic violence was found to be highly prevalent and alcohol emerged out be a major risk factor.

Keywords: Abuse, Addiction, Domestic violence.

How to cite this article: Bhatnagar A, Gupta SK, Hans G, Vikas H, Garg N, Pandey V. A Study on Prevalence of Domestic Violence among Women in Servant's Quarters of a Tertiary Care Hospital in North India. Int J Res Foundation Hosp Healthc Adm 2018;6(2):57-62.

Source of support: Nil

Conflict of interest: None

\section{INTRODUCTION}

Domestic violence (DV) is prevalent among women in India and has been related to poor mental and physical health consequences. ${ }^{1}$ It is considered similar to violence against women and is described as a phenomenon influenced by multiple determinants. ${ }^{2}$ It refers to needs of domination, the hierarchy of authority and obliteration of the other which can be used consciously in marriages as a path for the subordination of women by their partners. ${ }^{3}$

World Health Organization (WHO) defines DV as"the range of sexually, psychologically and physically coercive acts used against adult and adolescent women by current or former male intimate partner declaring it a public health epidemic". ${ }^{4}$

The Protection of Women from Domestic Violence Act (PWDVA), 2005 defines domestic violence as "any act, omission or commission or conduct of the respondent, which includes the threat or actual abuse ${ }^{\prime 5}$ In India, a National Family Health Survey (NFHS) III 2005 to 2006 , carried out in 29 states found that $37.2 \%$ of women experienced violence after marriage, $87 \%$ were spousal violence. $^{6}$ After implementation of PWDVA, the data from 16 states in NFHS-4 (2014-2015) shows a substantial decline among states, implying a maximum a fall of $15.8 \%$ in 10 years for spousal violence.

Among various proposed causes of DV and its increasing frequency in India are deep-rooted patriarchal roles of males and long-standing societal norms that propagate women as inferior throughout their lifespan. ${ }^{7}$ It can be manifested in form of physical, psychological, financial, emotional, social isolation, verbal or coercive control, etc. Several studies have found significance of factors that are associated with DV including individual's factor (young age, 
heavy drinking, depression, personality disorders, low academic achievement, low income, witnessing or experiencing violence as a child, employment, drug addiction, poor housing, childhood abuse) relationship factors (marital conflict, marital instability, male dominance in the family, economic stress, poor family functioning), community factors (weak community sanctions against domestic violence, poverty, low social capital) and societal factors (traditional gender norms, social norms supportive of violence). DV has substantial public health consequences, which includes general health and reproductive health in a woman. It can be chronic pain/fatigue, injuries, fractures, disability, psychiatric comorbidities, unwanted pregnancy, sexually transmitted diseases, and post-traumatic stress disorders. Also, it has a bad influence on the economic progress of a country in the form of increased economic costs including loss of woman's labor hours and healthcare costs. ${ }^{8,24}$ Children are also known to suffer from health consequences, in the long run, having symptoms like depression and anxiety, externalizing behaviors like aggression and trauma-related symptoms in children and adolescents. They are likely to face troubles in domains like academic difficulties, high-risk sexual behaviors, substance abuse and adverse environmental risk factors like poverty, neglect, and malnutrition which further making their prognosis worse. DV is variable with the level of literacy, age, local social and cultural norms. It is important to assess this in a given geographical area in order to initiate supportive measures. 9

With this background, the present study was undertaken to find out the prevalence, types, causes, effect on women/children and the corrective measures of the domestic violence in the servant quarters of a tertiary care hospital in North India.

\section{METHODOLOGY}

A questionnaire-based cross-sectional study was conducted in the servant's quarters of a tertiary care multispecialty teaching hospital in North India. All women of age group 18 to 65 years residing in the servant's quarters who were available and consented to be a part of the study were distributed the questionnaire. Oral consent was obtained from all the participants in the study and they were explained about the details and intent of the study in a language they could easily understand. The study was conducted between March and September 2018. The ethical clearance was taken from the institutional ethics committee for conducting the study.

\section{Inclusion Criterion}

- Women residing in servant's quarters of AIIMS.
- Women aged 18 to 65 years and agreeing to give consent and available for participation in the study.

\section{Exclusion Criterion}

- Women not willing to be a part of the study.

- Women who were not available during the time of the visit.

A questionnaire was specifically developed by the authors for the purpose of collecting the details of the participants. A pilot study on 34 participants was conducted to ascertain the face and content validity of the questionnaire. It was validated using the subject's responses.

For the conduct of the study, a local guide was accompanied along with the corresponding author for better communication. The households of groups C and D employees were visited in all the 3 residential campuses of the hospital. The questionnaire was distributed to a female from each household who fulfilled our inclusion criteria. The participants were detailed about all the aspects of the study and informed that their identity will be kept confidential. Oral consent was taken before the registration of the subject. The participants were guided about all the sections of the questionnaire. A total of 206 females were enrolled in the study out of 428 households visited. The data was entered in Microsoft Excel software and analysis was done by using SPSS software version 20.

\section{RESULTS}

Out of the total sample size of 206, 75 (36.5\%) were affected and 110 (53.4\%) were unaffected from domestic violence. Table 1 shows the demographic profile of participants under three heading, i.e., patients having no history of domestic violence, patients having a history of the domestic violence and total. It shows that women of younger (37.3\%) age group are affected more with a mean age of 34 years. Out of 75 males practicing domestic violence, $63.38 \%$ (45) of them had barely completed school, $22.86 \%$ (8) graduates while $29.33 \%$ (22) had no education at all, it was found to be statistically significant. It was seen that domestic violence was seen most among the helpers $72 \%$ (54), 21.3\% (16) private jobs and 10\% (8) were having permanent jobs. $10.66 \%$ (8) were having a nuclear family whereas 56\% (42) were living in a joined with maximum 1 earning member (68\%) from which 10.6\% (8) had 1-3 members 32\% (24) 4-6 members and 57.07\% (43) had more than $6.58 .7 \%$ (44) had 1-2 children, $25.4 \%$ (19) had 3-4 children and 9(12\%) had more than 4 which was found to be statistically significant with domestic violence. $46.5 \%$ had completed 1 to 5 years of marriage, $33.4 \%$ completed $5-10$ years while $14.5 \%$ had more than 10 years marriage which was proved to be significant. 
Table 1: Demographic profile of participants

\begin{tabular}{|c|c|c|c|c|c|c|c|}
\hline \multirow[b]{2}{*}{ Demographic factors } & & \multicolumn{2}{|c|}{$\begin{array}{c}\text { No history of domestic } \\
\text { violence }\end{array}$} & \multicolumn{2}{|c|}{$\begin{array}{c}\text { History of domestic } \\
\text { violence }\end{array}$} & \multicolumn{2}{|c|}{ Total } \\
\hline & & $N$ & $\%$ & $N$ & $\%$ & $N$ & $\%$ \\
\hline \multirow[t]{3}{*}{ Age } & $18-30$ & 52 & 62.65 & 31 & 37.3 & 83 & 40.1 \\
\hline & $30-45$ & 45 & 64.2 & 25 & 35.7 & 70 & 33.9 \\
\hline & $>45$ & 34 & 64.1 & 19 & 35.8 & 53 & 25.7 \\
\hline \multirow[t]{3}{*}{ Education of men } & Uneducated & 0 & 0 & 22 & 100 & 22 & 10.6 \\
\hline & Attended school & 54 & 54 & 45 & 45.9 & 99 & 48.05 \\
\hline & Graduate & 78 & 90.6 & 8 & 9.3 & 86 & 41.7 \\
\hline \multirow[t]{3}{*}{ Education of women } & Uneducated & 23 & 17.5 & 34 & 45.4 & 57 & 23.1 \\
\hline & Attended school & 83 & 63.3 & 40 & 53.4 & 123 & 59.7 \\
\hline & Graduate & 25 & 19.08 & 1 & 1.3 & 26 & 12.6 \\
\hline \multirow[t]{3}{*}{ Occupation of men } & Helper & 55 & 41.9 & 54 & 72 & 109 & 55.2 \\
\hline & Private job & 54 & 41.2 & 16 & 21.3 & 70 & 61.7 \\
\hline & Permanent job & 22 & 16.7 & 8 & 10.66 & 30 & 14.5 \\
\hline \multirow[t]{3}{*}{ Status of relationship } & Unmarried & 0 & 0 & 3 & 4 & 3 & 4 \\
\hline & Widow & 0 & 0 & 1 & 1.3 & 1 & 1.3 \\
\hline & Married & 131 & 100 & 71 & 94.7 & 202 & 98.05 \\
\hline \multirow[t]{2}{*}{ Type of family } & Nuclear & 61 & 46.5 & 33 & 44 & 94 & 45.63 \\
\hline & Joint & 70 & 53.4 & 42 & 56 & 112 & 54.36 \\
\hline \multirow[t]{3}{*}{ Duration of marriage } & $1-5 y e a r s$ & 31 & 23.6 & 35 & 46.5 & 66 & 32.03 \\
\hline & $5-10$ years & 30 & 22.9 & 25 & 33.4 & 55 & 26.7 \\
\hline & More than 10 years & 70 & 53.4 & 19 & 14.5 & 89 & 43.2 \\
\hline \multirow[t]{2}{*}{ Earning member } & 1 & 50 & 38.1 & 51 & $68 \%$ & 128 & 49.02 \\
\hline & $1-2$ & 81 & 61.8 & 24 & 32 & 113 & 50.97 \\
\hline \multirow{3}{*}{$\begin{array}{l}\text { Total number of } \\
\text { members }\end{array}$} & $1-3$ & 14 & 10.6 & 8 & 10.6 & 22 & 10.67 \\
\hline & $4-5$ & 44 & 33.5 & 24 & 32 & 76 & 33 \\
\hline & $>6$ & 73 & 55.7 & 43 & 57.3 & 116 & 56.31 \\
\hline \multirow[t]{3}{*}{ Number of children } & $1-2$ & 33 & 25.1 & 44 & 58.7 & 77 & 37.37 \\
\hline & $3-4$ & 60 & 45.8 & 19 & 25.4 & 79 & 38.34 \\
\hline & $>4$ & 20 & 15.2 & 9 & 12 & 32 & $14 \%$ \\
\hline \multirow[t]{2}{*}{ Satisfaction with life } & Yes & 85 & 64.8 & 23 & 30.7 & 108 & 52.42 \\
\hline & No & 46 & 35.11 & 52 & 69.4 & 98 & 47.5 \\
\hline
\end{tabular}

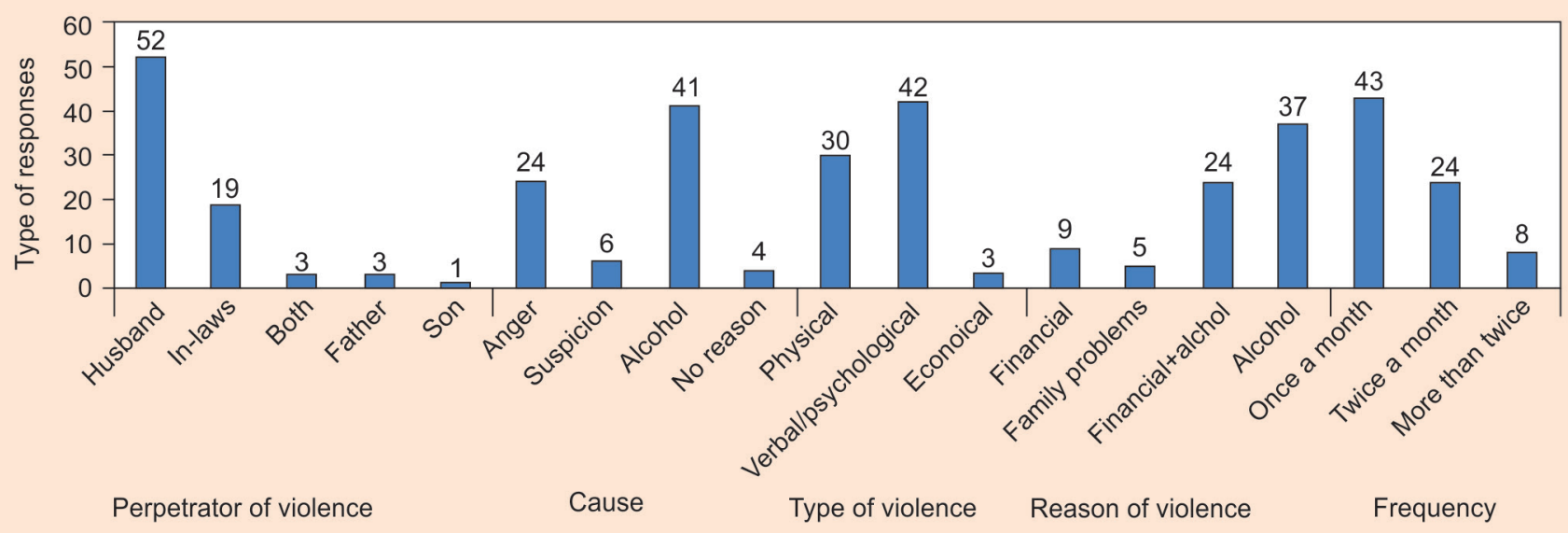

Graph 1: Magnitude, type, and cause of violence

Table 2 and Graph 1 deals with data regarding the magnitude, cause, type, reasons and frequency of domestic violence. The data presented here is out of the affected population, i.e., $75,(36.4 \%)$.
Among the affected population, 54.6\% complained alcohol to be the main cause of violence followed by anger $(32 \%)$, suspicion $(8 \%)$ and no reason $(5.3 \%)$. The most common type of violence was psychological (56\%) 
Table 2: Magnitude, type, and cause of violence

\begin{tabular}{llll}
\hline Magnitude of DV & Affected & 75 & $36 \%$ \\
& Nonaffected & 110 & $53.3 \%$ \\
\hline Perpetrator of violence & Husband & 52 & $69.3 \%$ \\
& In-laws & 19 & $25.4 \%$ \\
& Both & $5.4 \%$ & $4 \%$ \\
& Father & 3 & $1.3 \%$ \\
\hline Cause & Anger & 3 & $32 \%$ \\
& Suspicion & 1 & $8 \%$ \\
& Alcohol & 24 & $54.6 \%$ \\
\hline Type of violence & No reason & 6 & $5.3 \%$ \\
\hline Reason of violence & Vhysical & 41 & $40 \%$ \\
& Ecrbal/psychological & 4 & $56 \%$ \\
& Financial & 30 & $6 \%$ \\
\hline Frequency & Family problems & 42 & $12 \%$ \\
& Financial+alcohol & 3 & $6.7 \%$ \\
& Alcohol & 9 & $32 \%$
\end{tabular}

physical and verbal (40\%), economical (4\%) happening once a month $(57.33 \%)$, twice a month $(32 \%)$ and thrice a month (10.67\%).

There were a total of $57.7 \%$ (119) men suffering from alcohol addiction out of which $85.3 \%$ (64) practiced domestic violence whereas $14.7 \%$ (11) did not have any addiction yet practiced domestic violence. This result was found to be statistically significant.

During an episode of domestic violence out $75,17.3 \%$ had severe health effect whereas $36 \%$ had less severe effects. $49.33 \%$ have suffered from serious injuries like a fracture, laceration, contusion, and bruises $30 \%$ has mental instability and 23\% from chronic fatigue out of which only $22.67 \%$ had consulted a doctor.

Out of $75,39.4 \%$ women coped up by complaining to their parents, $49.4 \%$ by crying, $16 \%$ left house, and $4 \%$ by being violent with children. Concrete steps were taken by involving police $(2.6 \%)$, family and friends $(24 \%)$ and by taking a superstitious step $(6.1 \%)$ out of which improvement was seen only in $4.1 \%{ }^{3}$

In this study, it was found that out of 206, 53.3\% (110) were aware of the concept of domestic violence maximum among the educated section of women (75\%).

\section{DISCUSSION}

The prevalence of DV in our study was found to be $36.4 \%$ corresponding to data obtained by studies conducted in south India $(52.7 \%),{ }_{1}^{10}$ East India (52\%), ${ }_{1}^{11}$ and Mumbai ${ }^{12}$
(36.9\%). According to $\mathrm{WHO}, 37.7 \%$ of South-East Asia has DV, $37 \%$ of the east-Mediterranean region, $36.6 \%$ SouthAfrican region and $29.8 \%$ in the regions of America. ${ }^{13}$

According to this study, the husbands were the usual perpetrator of violence $(69.6 \%)$ similar to other studies conducted in different regions of India. ${ }^{14}$

A study conducted in Goa by Kamat et al. ${ }^{15}$ reported that illiterate women suffer 4 times more than the educated and our study found a similar association where $43 \%$ have no education and $53 \%$ barely completed their high school. According to our study, $41.4 \%$ of women belonged to the age group 18 to 30 years with a mean age of 34.4 years which is in concordance with a study by Fahmy et al. among 18 to 50 years who found a significantly higher percentage of domestic violence in younger women (less than 30 years). ${ }^{16}$ Women in the younger age group were currently facing domestic violence while women in older age groups gave a history of life experience of domestic violence.

The per capita difference between both the groups was found to be insignificant because the study sample selected had similar salaries. In our study, we found that domestic violence was more in joined families than nuclear which is in agreement with a study conducted by Fernandez. ${ }^{17}$ It was observed that violence was found more in the early years of marriage rather than later and also a statistically meaningful relationship with a number of family members which is in with the results obtained in a study conducted in Iran. ${ }^{18}$ 
In our study it was observed that only $37.8 \%$ were satisfied with their lives and $54.44 \%$ were not able to bear expenses which are in line with the results of the study conducted by Lucena et al. ${ }^{19}$ which showed that there is an association between domestic violence and poor quality of life index. The most common type of violence was seen as psychological in form of verbal abuses and isolation followed by physical which was similar with findings of a study by Shrivastava et al. ${ }^{12}$ who found total prevalence of domestic violence in Mumbai to be $36.9 \%$ with verbal to be the most common form of domestic violence in 87 (86.1\%) followed by physical violence in $64(63.4 \%)$ and other type violence among 24 (23.8\%). Physical violence is prevalent in $40 \%$ of participants corresponding to the data of NFHS-3 for the state Tamil Nadu (49\%). ${ }^{20}$

The most common consequence suffered by females was psychological (verbal) $56 \%$ which corresponds to studies from North Bengal (54.5\%). ${ }^{21}$

Domestic violence happening in front of children and adolescents also has adverse effects on them in the form of depressive symptoms, personality disorders, anti-social behavior, misbehavior and indulgent in bad habits like gambling and alcohol. Such results are also evidenced in various studies. ${ }^{22}$

A study conducted by Klap et al. ${ }^{23}$ in US stated that only $7 \%$ of women reported were ever asked about domestic violence or family violence by a general practitioner of which $46 \%$ were asked in a primary care setting, and $24 \%$ were asked in a mental health specialty setting which stresses on the need of screening since such issues are not reported by women voluntarily. By screening not only will it help to increase their level awareness but also can help to know the root cause of any condition been presented in OPD for optimum care of the patient.

The likelihood of DV occurrence was common among women who reported problem drinking by their partners $(76 \%)$. Alcohol was responsible in $49.33 \%$ cases as a single factor giving rise to any fight/argument resulting in violence. This is supported by evidence from previous studies conducted in Ghana, ${ }^{24}$ North India, ${ }^{25}$ Bangladesh, ${ }^{26}$ Haiti, ${ }^{27}$ and Kolkata ${ }^{28}$ making alcohol the most common risk factor of domestic violence against women. Another study conducted by White et al. ${ }^{29}$ also shows that heavy drinking by partners put women at greater risk for female victimization. It is shown that alcohol operates as a situational factor, increasing the probability of violence by decreasing inhibitions, clouding decision making and disabling an individual's ability to think about consequences. ${ }^{30}$

In our study, $50 \%$ of women had compromised with the situation, which is in agreement with other studies (2012). ${ }^{31}$ The results of several other studies indicate that intervening social support acts as an external medium that reduces domestic violence in families. ${ }^{32}$ This correlation shows compassionate relationships peripheral to the family can promote healthy behaviors inside the family, and how the presence of social support may act as a protective and an immunizing factor to omit violence towards women from their spouses. A study conducted by Vameghi ${ }^{33}$ and Gillum ${ }^{34}$ showed a direct relationship between the lack of social support and domestic violence.

However, in our study, it was observed that the steps taken by women against domestic violence did not show a significant improvement and it was seen only in $4 \%$ households.

\section{LIMITATION}

Since the sample was taken from a relatively homogenous sample of similar socio-economic background the generalisability of the study findings is difficult since it is well known that the prevalence varies to a great extent in different socio-economic conditions.

\section{CONCLUSION AND RECOMMENDATIONS}

- Domestic violence is highly prevalent among females in the servant's quarter.

- Alcohol addiction, low education status in men, younger age and number of family members are found to be major risk factors.

- Psychological effects on women followed by chronic fatigue and a bad influence on children are found to be major after-effects of domestic violence.

- Healthcare system can play a vital role by screening women first as a part of examination increasing their awareness and diagnoses of any condition arising from it.

- Further, analyses should be done in relation to the mental health of women suffering from DV and de-addiction services should be offered to the spouses of women suffering from domestic violence

- Self-help groups/ASHA help should be taken to carry out mass awareness programmes among illiterate women about their legal rights and domestic violence act

- Overall, education should be increased among girls and boys from a young age

\section{REFERENCES}

1. Kalokhe A, del Rio C, Dunkle K, Stephenson R, Metheny $\mathrm{N}$, Paranjape A, et al. Domestic violence against women in India: A systematic review of a decade of quantitative studies. Global public health. 2017 Apr 3;12(4):498-513.

2. Garcia LP, Freitas LRS, Höfelmann DA. Avaliaçãodoimpactoda Lei Maria da Penha sobre a mortalidade de mulheres por 
agressões no Brasil, 2001-2011. EpidemiolServSaude. 2013; 22(3):383-394.

3. Bandeira LM. Violência de gênero a construção de um campo teórico e de investigação. Rev Soc Estado. 2014;29(2):449-469.

4. Koenig MA, Lutalo T, Zhao F, Nalugoda F, Wabwire-Mangen F, Kiwanuka N, Wagman J, Serwadda D, Wawer M, Gray R, Bull World Health Organ. 2003;81(1):53-60.

5. Ekta Law Agency; The Protection of Women from Domestic Violence Act, 2005. Allahabad.

6. National family health survey 3, India, 2005-06. Goa, Mumbai: IIPS; 2009. International Institute of Population Sciences and Macro International.

7. Gundappa A, Rathod PB. Violence against Women in India: Preventive measures. Indian Streams Research Journal. 2012;2(4):1-4.

8. Pandey MK, Singh P, Yadav RA. Domestic Violence and Women's Health in India: Evidence from Health Survey. University Library of Munich, Germany. 2008. [Last cited on 2018 May 23].

9. United Nations Population Fund. A Practical Approach to Gender-based Violence. UNFPA.

10. George J, Nair D, Premkumar NR, Saravanan N, Chinnakali P, Roy G. The prevalence of domestic violence and its associated factors among married women in a rural area of Puducherry, South India, J Family Med Prim Care. 2016 Jul-Sep; 5(3):672-676.

11. Babu BV, Kar SK. Domestic violence against women in eastern India: a population-based study on prevalence and related issues. BMC Public Health. 2009 Dec;9(1):129.

12. Shrivastava PS, Shrivastava SR. A Study of Spousal Domestic Violence in an Urban Slum of Mumbai. Int J Prev Med. 2013 Jan; 4(1):27-32.

13. WHO. Global and regional estimates of violence against women: Prevalence and health effects of intimate partner violence and non-partner sexual violence.; 2013

14. Kaur S, Patidar AB, Sharma S. Domestic violence and its contributory factors among married women in selected slums of Ludhiana, Punjab. Nurs Midwifery Res J. 2014;10:30-35.

15. Kamat U, Ferreira AM, Motghare DD, Kamat N, Pinto NR. A cross-sectional study of physical spousal violence against women in Goa. Healthline. 2010;1:34-40.

16. Fahmy HH, Abd El-Rahman SI. Determinants and health consequences of domestic violence among women in reproductive age at zagazig district, Egypt. J Egypt Public Health Assoc. 2008;83(1-2):87-106.

17. Mohammadi F, Mirzaie R. The investigation of social factors affecting violence against women, case study in Ravansar city. Social Studies of Iran Journal. 2012;6(1):101-103.

18. Fernandez M. Domestic violence by extended family members in India: Interplay of gender and generation. Journal of Interpersonal Violence. 1997;12(3):433-455.

19. Lucena KD, Vianna RP, Nascimento JA, Campos HF, Oliveira EC. Association between domestic violence and women's quality of life. Revista latino-americana de enfermagem. 2017;25.

20. International Institute for Population Sciences (IIPS), Macro International. National Family Health Survey (NFHS-3), India, 2005-2006: Tamil Nadu. Mumbai: International Institute for Population Sciences; 2008.

21. Ray K, Chakraborty M, Roy H, Gupta S. Violence against women: Evidence from a cross sectional study in urban area of North Bengal. Al Ameen J Med Sci. 2012;5:157-164.

22. Kitzmann KM, Gaylord NK, Holt AR, Kenny ED. Child witnesses to domestic violence: a meta-analytic review. Journal of consulting and clinical psychology. 2003 Apr;71(2):339-352.

23. Klap R, Tang L, Wells K, Starks SL, Rodriguez M. Screening for domestic violence among adult women in the United States. J Gen Intern Med. 2007 May 1;22(5):579-584.

24. Adjah ES, Agbemafle I. Determinants of domestic violence against women in Ghana. BMC public health. 2016 Dec;16(1):368.

25. Koenig MA, Stephenson R, Ahmed S, Jejeebhoy SJ, Campbell J. Individual and contextual determinants of domestic violence in North India. J Am J Public Health. 2006 Jan;96(1):132-138.

26. Dalal K, Rahman F, Jansson B. Wife abuse in rural Bangladesh. J Biosoc Sci. 2005 Jul;61(2):343-264.

27. Gage A. Women's experience of intimate partner violence in Haiti. J Soc Sci Med. 2005 Jul; 61(2):343-364.

28. Sinha A, Mallik S, Sanyal D, Dasgupta S, Pal D, Mukherjee A. Domestic violence among ever married women of reproductive age group in a slum area of Kolkata. Indian J Public Health. 2012 Jan-Mar;56(1):31-36.

29. White HR, Chen PH. Problem drinking and intimate partner violence. J Stud Alcohol. 2002 Mar;63(2):205-214.

30. Gil-González D, Vives-Cases C, Alvarez-Dardet C, LatourPérez. Alcohol and intimate partner violence: do we have enough information to act? J Eur J Public Health. 2006 Jun; 16(3):279-285.

31. Shah SH, Rajani K, Kataria L, Trivedi A, Patel S, Mehta K. Perception and prevalence of domestic violence in the study population. Industrial psychiatry journal. 2012 Jul;21(2):137-143

32. Abramsky T, Watts CH, Garcia-Moreno C, Devries K, Kiss $\mathrm{L}$, Ellsberg M, et al. What factors are associated with recent intimate partner violence? Findings from the WHO multicountry study on women's health and domestic violence. Public Health. 2011 Feb 16;11(1):109.

33. Vameghi R, Akbari SA, Majd HA, Sajedi F, Sajjadi H. The comparison of socioeconomic status, perceived social support and mental status in women of reproductive age experiencing and not experiencing domestic violence in Iran. Journal of injury and violence research. 2018 Jan;10(1):35-44.

34. Gillum TL, Sullivan CM, Bybee DI. The importance of spirituality in the lives of domestic violence survivors. Violence against women. 2006 Mar; 12(3):240-250. 